\title{
STUDI PERENCANAAN SPILLWAY MORNING GLORY PADA BENDUNG WAI WOKI KABUPATEN NGADA
}

\author{
Panji Prayoga $^{1}$, Leonardus Setia Budi Wibowo ${ }^{2}$, \\ Muhammad Shofwan Donny Cahyono ${ }^{3}$, Norman Ray ${ }^{4}$ \\ ${ }^{1}$ Panji Prayoga, Universitas Widya Kartika, email: panjiprayogaaa@gmail.com \\ ${ }^{2}$ Leonardus Setia Budi Wibowo, Universitas Widya Kartika, email: leonarduswibowo@widyakartika.ac.id \\ ${ }^{3}$ Muhammad Shofwan Donny Cahyono, Universitas Widya Kartika, email: \\ shofwandonny@widyakartika.ac.id \\ ${ }^{4}$ Norman Ray, Universitas Widya Kartika, email: gasman_f14@yahoo.com
}

\begin{abstract}
ABSTRAK
Bangunan spillway adalah salah satu bagian komponen suatu bendungan yang berfungsi untuk melindungi tubuh bendungan dari bahaya pelimpasan (overtopping) pada saat banjir. Bendungan Wai Woki yang menjadi objek pada perencanaan ini, direncanakan menggunakan spillway tipe morning glory. Spillway ini merupakan suatu struktur yang digunakan untuk mengendalikan pelepasan air yang mengalir dari bendungan ke daerah hilir, berbentuk menara/cerobong yang sangat efektif untuk bendungan yang tidak memiliki ruang yang cukup untuk pelimpah jenis lainnya.

Perencanaan ini terdiri dari analisis yang meliputi : analisis hidrologi, hidrolika, analisis stabilitas, dan analisa struktur. Adapun bendungan yang direncanakan memiliki periode ulang 100 tahun dengan luas DAS sebesar 38,25 $\mathrm{km}^{2}$ dan panjang sungai 9,61 km serta data hujan harian sebanyak 10 tahun. Dari hasil kajian yang diperoleh elevasi puncak bangunan spillway adalah $+120.00 \mathrm{Mdpl}$ dengan debit banjir maksimum $90,39 \mathrm{~m}^{3} /$ det pada elevasi +121.25 . Tinggi bangunan 30 meter dengan diameter puncak 6 meter dan diameter konduit 4,5 meter. Panjang konduit 212,065 meter. Serta tebal dinding 0,40 meter dengan tulangan horisontal \& vertikal D24-150 mm.
\end{abstract}

Kata kunci: spillway morning glory, pelimpah corong, spillway

\section{PENDAHULUAN}

Air merupakan sendi utama kehidupan manusia, dimana bukan hanya untuk sekedar memenuhi kebutuhan mendasar manusia sebagai air minum, namun juga berfungsi untuk sumber penghidupan seperti mengairi lahan pertanian, perikanan, hingga pembangkit listrik, Pada musim penghujan, air berlimpah-limpah sehingga sungai tidak mampu lagi menampung aliran air dan akan menyebabkan adanya banjir. Sementara pada saat musim kemarau air berkurang, padahal kebutuhan air untuk rumah tangga, listrik, irigasi, dan lain-lain masih tetap berlangsung dan kondisi seperti inilah yang mengakibatkan terjadinya kekurangan air. Untuk itu perlu dibuat bendungan sebagai alternatif penyimpanan air.

Desa Pape yang terletak di Kabupaten Ngada, Nusa Tenggara Timur, merupakan salah satu desa yang mengalami kesulitan untuk pasokan air bersih saat musim kemarau. Baik untuk keperluan jaringan irigasi maupun untuk keperluan hidup masyarakatnya sehari-hari. Daerah irigasi di Desa Pape memiliki luas lahan sekitar $75 \mathrm{Ha}$, namun hanya $40 \mathrm{Ha}$ saja lahan fungsional yang penggarapannya satu kali dalam setahun dan luas lahan potensialnya masih ada $35 \mathrm{Ha}$ lagi. Adapun sumber air yang mengairi daerah irigasi Desa Pape tersebut, yaitu berasal dari sungai Wai Woki. 


\section{NAROTAMA JURNAL TEKNIK SIPIL \\ e-ISSN: 2460-3430 \\ VOLUME 4 NOMOR 1 JUNI 2020}

Salah satu usaha pemerintah untuk mengatasi masalah tersebut adalah dengan membangun sebuah bendungan. Dimana bendungan tersebut direncanakan menggunakan pelimpah (spillway) samping. Tujuan dibangunnya spillway ini adalah untuk meluapkan debit aliran air lebih atau banjir pada tampungan bendungan yang menyebabkan naiknya muka air dan untuk menghindari overtopping pada bendungan. Untuk itu dalam pembahasan ini, penulis mencoba memberikan perbandingan pada efektivitas spillway eksisting dengan spillway rencana, yang dimana penulis merencanakan pembangunan spillway jenis morning glory.

Spillway Morning Glory merupakan suatu struktur yang digunakan untuk mengendalikan pelepasan air yang mengalir dari bendungan ke daerah hilir, berbentuk menara/cerobong yang sangat efektif untuk bendungan yang tidak memiliki ruang yang cukup untuk pelimpah jenis lainnya. Bagian dasar spillway ini merupakan struktur yang digunakan untuk melepaskan air secara teratur. Didalam sebuah perhitungan dan perencanaan sebuah spillway, tentunya membutuhkan sebuah pertimbanganpertimbangan agar didapat hasil efektif dan efisien terutama dari segi dimensi, kestabilan dan strukturnya sendiri. Spillway Morning Glory ini nantinya, akan dirancang untuk beroperasi dalam keadaan terendam atau tenggelam. Dimana spillway ini akan dibandingkan dengan spillway eksisting yang ada di lokasi.

\section{METODE PENELITIAN}

Tahap awal penelitian ini adalah studi literatur dan pengumpulan data. Studi literatur dilakukan dengan mempelajari dan memahami teori-teori atau buku-buku referensi pendukung yang akan digunakan sebagai dasar dan acuan untuk digunakan dalam menghitung dan menganalisa permasalahan-permasalahan yang nantinya didapat pada saat pengerjaan tugas akhir ini. Serta dengan mempelajari studi-studi yang telah dilakukan, berkaitan dengan pembangunan Spillway Morning Glory. Untuk pengumpulan datanya yaitu diperlukan antara lain data curah hujan selama 10 tahun dari dua stasiun hujan yang berbeda, peta topografi lokasi perencanaan, dan data tanah di lokasi perencanaan.

Untuk analisa perencanaan dibagi kedalam dua tahap global, yaitu analisa hidrologi dan analisa hidrolika. Dimana analisa hidrologi bertujuan untuk mengolah data curah hujan yang didapat untuk mendapatkan debit banjir rancangan yang digunakan untuk menentukan dimensi pelimpah yang selanjutnya dihitung pada proses analisa hidrolika. Diagram alur pada pengerjaan tugas akhir ini, dapat dilihat pada Gambar 1 dibawah ini : 

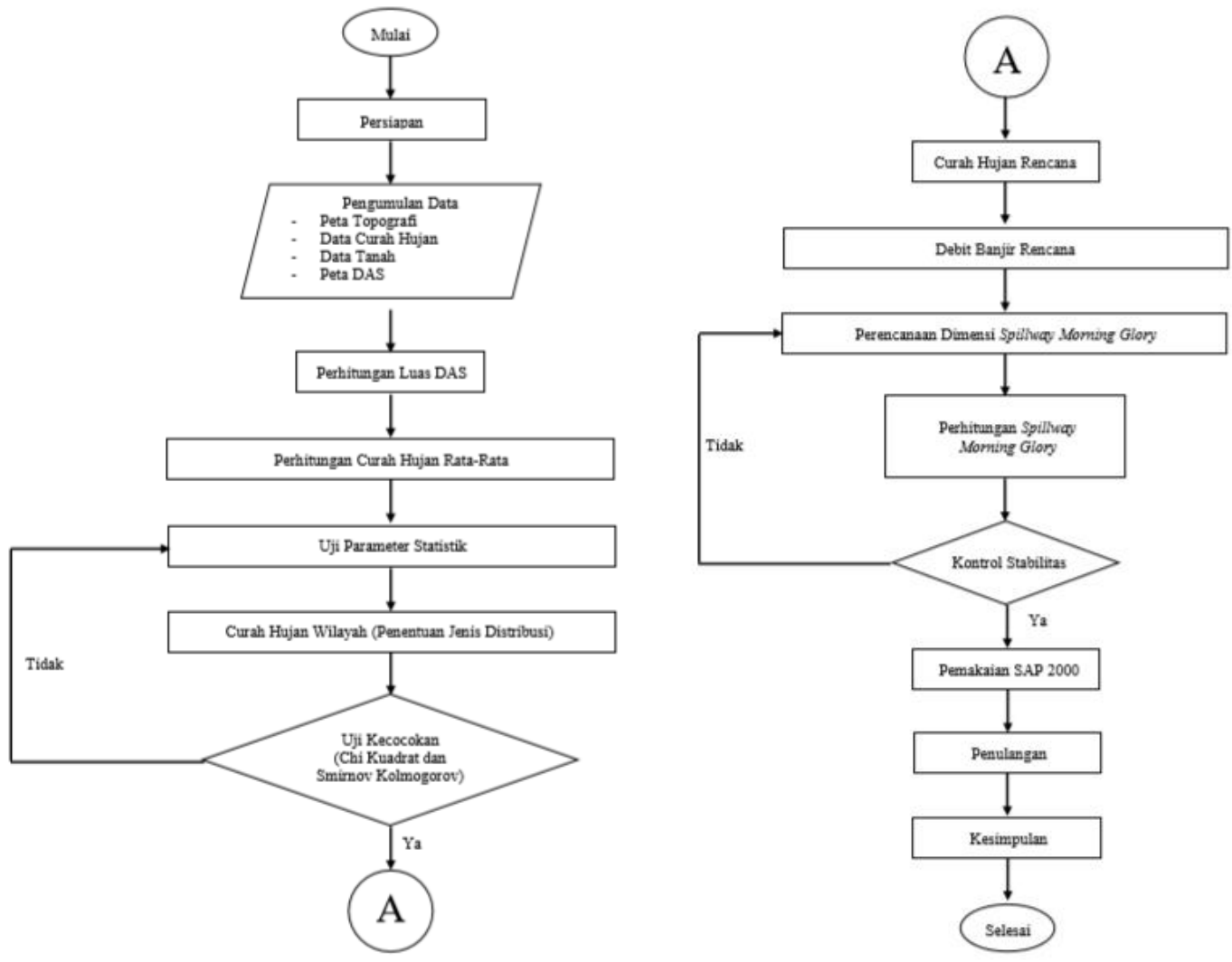

Gambar 1: Diagram Alur Penelitian

\section{HASIL DAN PEMBAHASAN}

\section{Analisa Hidrologi}

Analisa hidrologi merupakan proses yang analisa yang dilakukan untuk mengolah data curah hujan yang didapat dari dua stasiun hujan yang berbeda untuk mendapatkan debit banjir rancangan dengan periode ulang 100 tahun (periode ulang rencana). Data curah hujan maksimum dari dua stasiun hujan yang penulis gunakan sebagai sumber data, dapat dilihat pada Tabel 1. berikut ini :

Tabel 1: Curah Hujan Maksimum Stasiun Uji

\begin{tabular}{|c|c|c|}
\hline \multirow{2}{*}{ Tahun } & \multicolumn{2}{|c|}{ Curah Hujan Harian Maksimum (mm) } \\
\cline { 2 - 3 } & Stasiun Bajawa & Stasiun Golewa \\
\hline 2009 & 89 & 56 \\
\hline 2010 & 90 & 82 \\
\hline 2011 & 281,5 & 691 \\
\hline 2012 & 358 & 691 \\
\hline 2013 & 419 & 556 \\
\hline 2014 & 358 & 269 \\
\hline 2015 & 358 & 428 \\
\hline 2016 & 807 & 490 \\
\hline 2017 & 574 & 490 \\
\hline 2018 & 654 & 383 \\
\hline
\end{tabular}

\section{Curah Hujan Rencana}


Metode distribusi sebaran yang digunakan dalam menghitung curah hujan rencana adalah metode Log Pearson Type III. Dimana rumus yang digunakan adalah sebagai berikut :

$\log X=\log X r t+(k x \operatorname{Slog} x)$

$\mathrm{X} \quad=10 \log \mathrm{X}$

Untuk hasil perhitungannya dapat dilihat pada Tabel 2. berikut ini :

Tabel 2: Curah Hujan Rencana Periode Ulang 100 Tahun

\begin{tabular}{|c|c|c|c|c|c|c|c|c|}
\hline No & $\begin{array}{c}\text { Periode } \\
\text { Ulang } \\
\text { (Tahun) }\end{array}$ & $\begin{array}{c}\text { Peluang } \\
(\boldsymbol{\%})\end{array}$ & $\mathbf{S}_{\mathbf{L o g} \mathbf{X}}$ & $\mathbf{L o g} \mathbf{X r t}$ & $\mathbf{C s}$ & $\mathbf{K}$ & $\mathbf{L o g} \mathbf{X}$ & $\mathbf{X}(\mathbf{m m})$ \\
\hline 1 & 2 & 50 & 0,3408 & 2,5233 & $-1,54$ & 0,2395 & 2,6049 & 402,6 \\
\hline 2 & 5 & 20 & 0,3408 & 2,5233 & $-1,54$ & 0,8245 & 2,8043 & 637,2 \\
\hline 3 & 10 & 10 & 0,3408 & 2,5233 & $-1,54$ & 1,0175 & 2,8701 & 741,4 \\
\hline 4 & 25 & 4 & 0,3408 & 2,5233 & $-1,54$ & 1,157 & 2,9176 & 827,2 \\
\hline 5 & 50 & 2 & 0,3408 & 2,5233 & $-1,54$ & 1,218 & 2,9384 & 867,7 \\
\hline 6 & 100 & 1 & 0,3408 & 2,5233 & $-1,54$ & 1,2575 & 2,9518 & 895,1 \\
\hline
\end{tabular}

Dimana :

$$
\begin{array}{ll}
\log X & =\text { logaritma curah hujan rencana untuk periode ulang (tahun) } \\
\mathrm{K} & =\text { Konstanta yang besarnya tergantung nilai Cs } \\
\log X r t & =\text { Harga rata-rata dari logaritma data } \\
\mathrm{n} & =\text { jumlah data } \\
\text { Slog } \mathrm{X} & =\text { Standar Deviasi dari Log X }
\end{array}
$$

\section{Curah Hujan Efektif Jam-Jaman}

Tujuan dalam proses perhitungan ini adalah untuk mendapatkan debit banjir rancangan dalam satuan waktu detik serta jam-jaman. Adapun rumus yang digunakan adalah sebagai berikut :

$\mathrm{Rt}=\mathrm{R} 24 / \mathrm{T} \times(\mathrm{T} / 1) 2 / 3$

\begin{tabular}{|c|c|c|c|c|c|c|c|}
\hline $\mathrm{Ti}$ & Rasio & \multicolumn{6}{|c|}{ Hujan Jam-Jaman (mm) } \\
\hline Jam & $(\%)$ & 2 th & 5 th & 10 th & 25 th & 50 th & 100 th \\
\hline 1,00 & 0,59 & 98,92 & 156,56 & 182,16 & 203,24 & 213,20 & 219,91 \\
\hline 2,00 & 0,15 & 25,53 & 40,41 & 47,02 & 52,46 & 55,03 & 56,76 \\
\hline 3,00 & 0,11 & 18,09 & 28,64 & 33,32 & 37,17 & 39,00 & 40,22 \\
\hline 4,00 & 0,09 & 14,37 & 22,75 & 26,47 & 29,53 & 30,98 & 31,95 \\
\hline 5,00 & 0,07 & 12,18 & 19,27 & 22,42 & 25,01 & 26,24 & 27,07 \\
\hline \multicolumn{2}{|c|}{ Hujan Efektif (mm) } & 169,10 & 267,62 & 311,39 & 347,41 & 364,45 & 375,92 \\
\hline \multicolumn{2}{|c|}{ Koefisien (C) } & 0,42 & 0,42 & 0,42 & 0,42 & 0,42 & 0,42 \\
\hline
\end{tabular}

Dalam perhitungan ini, diasumsikan bahwa T (lamanya hujan terpusat adalah 5 jam), sedangkan untuk hasil perhitungannya dapat dilihat pada Tabel 3. berikut ini :

Tabel 3: Curah Hujan Efektif Jam-Jaman 
Selanjutnya, grafik HSS Gama I akibat curah hujan 2 tahun, 5 tahun, 10 tahun, 25 tahun, 50 tahun dan 100 tahun dapat dilihat pada Gambar 3. dibawah ini :

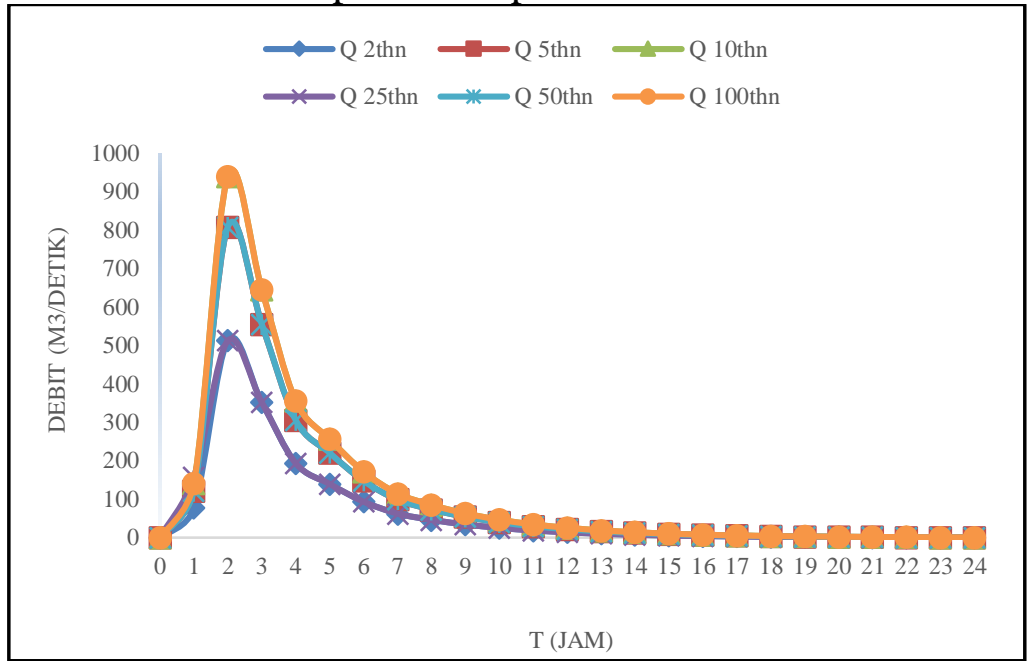

Gambar 2: Grafik Hidrograf Banjir Rencana

Dari grafik diatas, dapat diketahui bahwa Debit banjir maksimum yang terjadi pada periode ulang 100 tahun adalah 940,42 m3/dtk.

\section{Analisa Hidrolika}

Dalam merencanakan spillway perlu adanya beberapa pertimbangan sebelum merencanakan ke tahap selanjutnya. Adapun bahan-bahan pertimbangan yang telah diamati adalah sebagai berikut :

$\begin{array}{ll}\text { Elevasi puncak } & =+128,00 \mathrm{~m} \\ \text { Elevasi dasar } & =+88,00 \mathrm{~m} \\ \text { Luas genangan } & =750.000 \mathrm{~m}^{2} \\ \text { Sedimen } & =975.000 \mathrm{~m}^{3} \\ \text { Efektif } & =1.125 .000 \mathrm{~m}^{3} \\ \text { Total } & =2,1 \mathrm{Juta} \mathrm{m}^{3}\end{array}$

\section{Floud Routing}

Adalah proses yang dilakukan untuk mengetahui daya tampung waduk terhadap banjir rencana yang terjadi, oleh sebab itu maka dicari besarnya tampungan awal dan tampungan kedua untuk perhitungan outflow (storage function). Dimana, rumus yang digunakan adalah sebagai berikut :

$$
\begin{array}{ll}
\Psi & =\mathrm{S} / \mathrm{t}-\mathrm{Q} 0 / 2 . \\
\varphi & =\mathrm{S} / \mathrm{t}+\mathrm{Q} 0 / 2
\end{array}
$$

untuk perhitungannya dapat dilihat pada Tabel 4. berikut ini : 
NAROTAMA JURNAL TEKNIK SIPIL

e-ISSN: 2460-3430

VOLUME 4 NOMOR 1 JUNI 2020

Tabel 4: Perhitungan Floud Routing

\begin{tabular}{|c|c|c|c|c|c|c|}
\hline $\mathbf{t}$ & $\mathbf{I n f l o w}$ & $\mathbf{O u t f l o w}$ & $\boldsymbol{\psi}$ & $\boldsymbol{\phi}$ & Elevasi & $\mathbf{Q}$ \\
\hline $\mathbf{j a m})$ & $\mathbf{( m 3 / d e t i k )}$ & $\mathbf{( m 3 / d e t i k )}$ & $\mathbf{( m 3 / d e t i k )}$ & $\mathbf{( m 3 / d e t i k )}$ & $\mathbf{( m )}$ & $\mathbf{( m 3 / d e t i k )}$ \\
\hline 0 & 0,00 & 0,00 & 0,00 & 0,00 & 120,00 & 0,00 \\
\hline 1 & 141,78 & 11,69 & 65,17 & 76,86 & 120,28 & 11,69 \\
\hline 2 & 940,42 & 48,83 & 166,77 & 215,60 & 120,78 & 48,83 \\
\hline 3 & 646,15 & 88,41 & 205,79 & 294,20 & 121,23 & 88,41 \\
\hline 4 & 355,51 & 90,39 & 208,01 & 298,40 & 121,25 & 90,39 \\
\hline 5 & 256,40 & 89,40 & 206,90 & 296,30 & 121,24 & 89,40 \\
\hline 6 & 171,66 & 85,44 & 202,45 & 287,89 & 121,21 & 85,44 \\
\hline 7 & 114,92 & 69,58 & 184,67 & 254,26 & 121,04 & 69,58 \\
\hline 8 & 85,05 & 56,46 & 172,89 & 229,35 & 120,88 & 56,46 \\
\hline 9 & 62,95 & 44,87 & 161,28 & 206,15 & 120,73 & 44,87 \\
\hline 10 & 46,59 & 34,85 & 139,36 & 174,22 & 120,61 & 34,85 \\
\hline 11 & 34,48 & 27,34 & 122,92 & 150,26 & 120,52 & 27,34 \\
\hline 12 & 25,52 & 21,86 & 104,52 & 126,37 & 120,44 & 21,86 \\
\hline 13 & 18,89 & 17,41 & 87,30 & 104,71 & 120,37 & 17,41 \\
\hline 14 & 13,98 & 12,96 & 70,09 & 83,05 & 120,30 & 12,96 \\
\hline 15 & 10,35 & 9,78 & 57,80 & 67,58 & 120,25 & 9,78 \\
\hline 16 & 7,66 & 8,22 & 48,55 & 56,77 & 120,21 & 8,22 \\
\hline 17 & 5,67 & 6,65 & 39,30 & 45,95 & 120,17 & 6,65 \\
\hline 18 & 4,19 & 5,09 & 30,05 & 35,14 & 120,13 & 5,09 \\
\hline 19 & 3,10 & 3,52 & 20,81 & 24,33 & 120,09 & 3,52 \\
\hline 20 & 2,30 & 2,35 & 13,87 & 16,22 & 120,06 & 2,35 \\
\hline 21 & 1,70 & 5,48 & 32,37 & 37,84 & 120,04 & 5,48 \\
\hline 22 & 1,26 & 0,78 & 4,62 & 5,41 & 120,02 & 0,78 \\
\hline 23 & 0,93 & 0,39 & 2,31 & 2,70 & 120,01 & 0,39 \\
\hline 24 & 0,69 & 0,00 & 0,00 & 0,00 & 120,00 & 0,00 \\
\hline & & & & & & \\
\hline
\end{tabular}

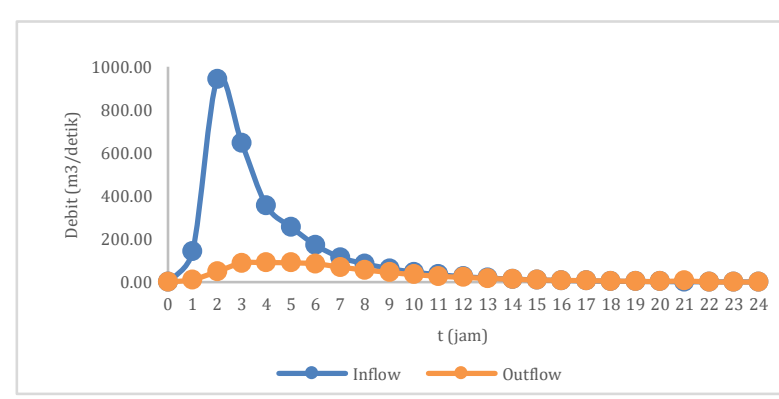

Gambar 4. Grafik Flood Routing

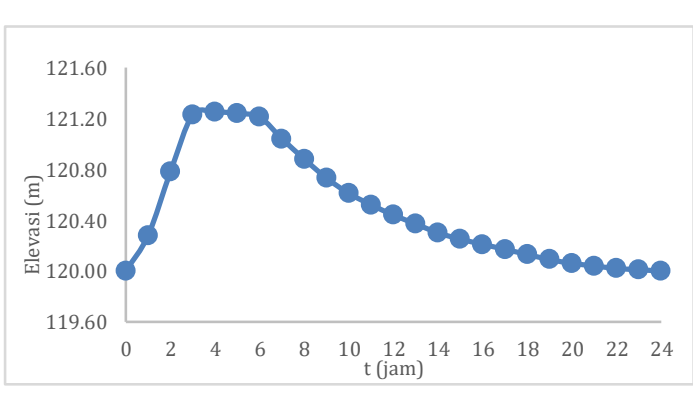

Gambar 5. Grafik Hubungan Elevasi terhadap Waktu Outflow

Dari perhitungan diatas didapatkan bahwa Inflow maks sebesar $940,42 \mathrm{~m}^{3} /$ detik dan Qmaks 90,39 $\mathbf{m}^{3} /$ dt. Sedangkan pada Gambar 5 dapat diketahui $\mathrm{H}$ maksimal pada elevasi $\mathbf{+ 1 2 1 , 2 5}$ mdpl atau berada $\mathbf{1 , 2 5} \mathbf{m}$ diatas puncak spillway.

\section{Perencanaan Saluran Konduit}

Dalam merencanakan ukuran konduit harus diperkirakan sehingga tidak akan mengalirkan aliran lebih dari $75 \%$ aliran penuh (dalam luas) debit maksimum pada ujung hilir. Hal ini untuk dapat mengijinkan masuknya udara, gelombang dan lainnya (Departemen PU, 1999:99). Pada perencanaan konduit, asumsi awal untuk diameter telah direncanakan dengan $\mathrm{D}=2,6$ meter dengan debit maksimum spillway 90,39 
$\mathrm{m}^{3} / \mathrm{dtk}$. Adapun rumus yang digunakan dalam mengontrol diameter saluran konduit adalah sebagai berikut :

$\mathrm{Z}=(\mathrm{Q}) /(\sqrt{\mathrm{g}})$

$\mathrm{Z} / \mathrm{Do} 2,5$

Do $>$ Hc (diameter saluran diterima).

$$
\begin{aligned}
& (100 \% / 75 \%) \times 90,39=120,52 \mathrm{~m} 3 / \mathrm{dtk} \\
& \mathrm{Z} \quad=(\mathrm{Q}) /(\sqrt{\mathrm{g}}) \\
& =120,52 /(\sqrt{ } 9,81)=21,65 \\
& \mathrm{Z} / \mathrm{Do} 2,5=21,65 / 2,62,5=2 \\
& \mathrm{Hc} / \mathrm{Do} \quad=2 \\
& \mathrm{Hc} \quad=2,1 \times 3=6
\end{aligned}
$$

Karena, Hc > Do maka bisa dipastikan bahwa tunnel tersebut akan mengalami kondisi full pipe. Agar tunnel tidak terjadi aliran penuh ( full pipe), maka diameter tunnel direncanakan kembali. Hal ini untuk dapat mengijinkan masuknya udara, gelombang dan lainnnya.

Oleh sebab itu, diameter tunnel direncanakan kembali menjadi $4,5 \mathrm{~m}$

$$
\begin{aligned}
& \mathrm{D}=4,5 \mathrm{~m} \\
& \mathrm{Z}=(\mathrm{Q}) /(\sqrt{\mathrm{g}}) \\
& =137,03 /(\sqrt{ } 9,81)=21,65 \\
& \mathrm{Z} / \mathrm{Do} 2,5 \quad=21,65 / 4,52,5=0,5 \\
& \mathrm{Hc} / \mathrm{Do} \quad=0,5 \\
& \mathrm{Hc} \quad=0,5 \times 4,5=2,3 \mathrm{~m}
\end{aligned}
$$

Karena $\mathrm{Hc}<\mathrm{Do}$, maka diameter 4,5 m dapat diterima. Jadi total panjang konduit yang baru menjadi :

$$
\begin{array}{ll}
-\mathrm{L} 1 & =20 \mathrm{~m} \\
-\mathrm{L} 2 & =(2 \pi \mathrm{D}) / 4=(2 \pi 4,5) / 4=7,065 \mathrm{~m} \\
\text { - } \mathrm{L} 3 & =185 \mathrm{~m}
\end{array}
$$

Jadi, total panjang konduit adalah $212,065 \mathrm{~m}$ dengan tinggi bangunan pelimpah 30 meter dengan diameter puncak 6 meter dan diameter konduit 4,5 meter.

\section{Perencanaan Tebal Minimum Tunnel}

Ketebalan minimum biasanya adalah 6 inchi. Namun, karena ada beban eksternal maka memerlukan perencanaan tebal untuk menahan beban tekanan hidrostatik (USBR). Adapun rumus yang digunakan untuk menghirung ketebalan dinding saluran pelimpah adalah sebagai berikut :

$$
\begin{aligned}
\mathrm{hmin} & =\frac{\left(\frac{(m \times E s)+f s-(n \times f c, \text { ten })}{f s \times f c, t e n}\right) P \times D}{2}>6 \mathrm{in} \ldots \ldots . . . . \\
\mathrm{hmin} & =\frac{\left(\frac{(m \times E s)+f s-(n \times f c, \text { ten })}{f s \times f c, t e n}\right) P \times D}{2} \\
& =\frac{\left(\frac{(0,0003 \times 2.000 .000)+1.600-(7,8 \times 30)}{1600 \times 30}\right) 3 \times 450}{2}
\end{aligned}
$$




$$
\begin{aligned}
& =27,65 \mathrm{~cm}>6 \text { in }(=15,24 \mathrm{~cm}) \\
& =28 \mathrm{~cm}
\end{aligned}
$$

Dari hasil perhitungan di atas diketahui bahwa perhitungan tebal minimum tunnel adalah $\mathrm{d}=28 \mathrm{~cm}$. Sedangkan karena alasan ada tekanan hidrodinamis dan safety factor yang lebih baik, maka ketebalan pada spillway morning glory akan direncanakan dengan $\mathrm{t}=40 \mathrm{~cm}$.

\section{Perhitungan Stabilitas Spillway}

\section{A. Kontrol Guling}

$\frac{\text { Momen Penahan }}{\text { Momen Guling }} \geq \mathrm{SF}$

B. Kontrol Geser

$$
\frac{\left(\sum G-\sum U\right) \cdot f}{\sum H} \geq 1,2
$$

Dimana :

$\mathrm{f} \quad=$ koefisien gesekan

$\Sigma \mathrm{G} \quad=$ gaya vertikal total akibat berat sendiri

$\Sigma \mathrm{U} \quad=$ gaya uplift total

$\Sigma \mathrm{H} \quad=$ total selisih gaya horizontal

C. Kontrol Tegangan Tanah

$$
\begin{aligned}
& \text { e } \quad=\frac{B}{2}-\left(\frac{\sum \text { Mtahan }-\sum M \text { Guling }}{\sum V}\right) \\
& \sigma_{\text {maks }}=\frac{\sum V}{B}\left(1+\frac{6 x e}{B}\right) \leq \sigma_{\text {ijin }} \\
& \sigma_{\min }=\frac{\sum V}{B}\left(1-\frac{6 x e}{B}\right)>0
\end{aligned}
$$

\begin{tabular}{|c|c|c|c|c|c|c|c|c|c|c|}
\hline \multirow{2}{*}{ Kontrol } & \multicolumn{2}{|c|}{ Keadaan Kosong } & \multirow[t]{2}{*}{ Syarat } & \multicolumn{2}{|c|}{ Setinggi Mercu } & \multirow[t]{2}{*}{ Syarat } & \multicolumn{2}{|c|}{$\begin{array}{l}\text { Setinggi Air } \\
\text { Banjir }\end{array}$} & \multirow[t]{2}{*}{ Syarat } & \multirow[t]{2}{*}{ Ket. } \\
\hline & $\begin{array}{c}\text { Kondisi } \\
1\end{array}$ & $\begin{array}{l}\text { Kondisi } \\
2\end{array}$ & & $\begin{array}{c}\text { Kondisi } \\
1\end{array}$ & $\begin{array}{l}\text { Kondisi } \\
2\end{array}$ & & $\begin{array}{c}\text { Kondisi } \\
1\end{array}$ & $\begin{array}{c}\text { Kondisi } \\
2\end{array}$ & & \\
\hline Guli & 73,1 & 16,6 & 15 & 5,1 & 4,34 & $>15$ & 4,8 & 1,9 & 1,5 & $\overline{\mathrm{OK}}$ \\
\hline Geser & 30,61 & 443,63 & $\geq 1,2$ & 30,6 & 443,63 & $\geq 1,2$ & 30,7 & 44,2 & $\geq 1,2$ & OK \\
\hline$\sigma_{\text {maks }}$ & 519,07 & 529,3 & $\begin{array}{c}\leq \\
1073,4\end{array}$ & 481,1 & 491,3 & $\begin{array}{c}\leq \\
1073,4\end{array}$ & 479,9 & 490,1 & $\leq \frac{\leq}{1073,4}$ & OK \\
\hline
\end{tabular}

Dimana :

$\begin{array}{ll}\sigma \mathrm{maks} & =\text { tegangan tanah max. yang timbul } \\ \sigma \mathrm{min} & =\text { tegangan tanah min. yang timbul } \\ \Sigma \mathrm{V} & =\text { gaya vertikal total } \\ \mathrm{B} & =\text { lebar pondasi } \\ \mathrm{e} & =\text { eksentrisitas } \\ \sigma \mathrm{t} & =\text { tegangan tanah yang diijinkan }\end{array}$

Tabel 5: Rekapitulasi Stabilitas Spillway 
VOLUME 4 NOMOR 1 JUNI 2020

\begin{tabular}{l|l|l|l|l|l|l|l|l|l|l}
$\sigma_{\min }$ & 247,73 & 257,9 & $>0$ & 209,7 & 219,93 & $>0$ & 208,2 & 218,4 & $>0$ & OK
\end{tabular}

Dapat disimpulkan bahwa konstruksi spillway aman terhadap bahaya guling, bahaya geser, dan memenuhi syarat terhadap daya dukung tanah dasarnya, baik ditinjau dalam keadaan normal maupun gempa pada kondisi kosong, muka air normal, dan muka air banjir.

\section{KESIMPULAN}

Berdasarkan hasil perhitungan yang telah dilakukan, maka diperoleh beberapa kesimpulan sebagai berikut:

1. Besarnya debit inflow maksimum yang didapat dari hasil perhitungan hidrograf banjir rancangan adalah sebesar 940,42 m3/det, sedangkan debit outflow maksimumnya adalah sebesar 90,39 m3/det. Dengan elevasi muka air diatas pelimpah pada EL.+121,25 m. Serta puncak spillway berada pada EL.+120.00 mdpl.

2. Tinggi bangunan spillway morning glory 30,5 meter dengan diameter puncak 6 meter dan diameter konduit 4,5 meter. Sedangkan total panjang konduit adalah 212,065 meter. Dengan ketebalan dinding 0,40 meter dengan fc $30 \mathrm{Mpa}$.

3. Dari hasil analisis stabilitas dengan pertimbangan beban yang bekerja, maka dapat dikatakan bahwa konstruksi spillway aman terhadap bahaya guling, bahaya geser, dan memenuhi syarat terhadap daya dukung tanah dasarnya, baik ditinjau dalam keadaan normal maupun gempa pada kondisi kosong, muka air normal, dan muka air banjir.

4. Tulangan yang dipakai pada bangunan pelimpah adalah D24-150 dengan fy 400 $\mathrm{MPa}$.

5. Perbedaan yang timbul antara pelimpah morning glory dengan pelimpah samping adalah dari segi penggunaan lahan. Dimana pelimpah samping akan memerlukan lahan tambahan lagi yang berada disamping bendung untuk membangun pelimpah tersebut, sedangkan spillway morning glory, dapat dibangun di bendungan itu sendiri. Dimana mercu yang berbentuk silinder akan mengalirkan air menuju kolam olak melalui terowongan konduit yang telah direncanakan sebelumnya. Jadi, pelimpah morning glory tidak memerlukan lahan tambahan sebanyak pelimpah samping. 


\section{DAFTAR PUSTAKA}

1. Badan Standarisasi Nasional, 2002. Tata Cara perencanaan Ketahanan Gempa Untuk Bangunan Gedung, SNI 03-17262002. Jakarta: Standar Nasional Indonesia.

2. Bradley, J.N. 1952. "Prototype Behavior of Morning Glory Shaft Spillways". Colorado. Denfer Office.

3. Coleman, H. Wayne. Chapter 17. "Hydraulic Design of Spillway", Harza Engineering Company Chicago: Illinois.

4. Direktorat Penyelidikan Masalah Bangunan. 1983. Peraturan Pembebanan Indonesia Untuk Gedung 1983. Bandung : Yayasan Lembaga Penyelidikan Masalah Bangunan.

5. Robertus B N Dhongu, 2014. Perencanaan Bendung Wai Woki dan Sistem Jaringan Irigasi Desa Pape Kecamatan Bajawa Kabupaten Ngada. Malang: Institut Teknologi Malang

6. $\quad$ SK SNI M-18-1989-F. “Metode Perhitungan Debit Banjir”. DPU Pengairan.

7. Soemarto. 1999. "Hidrologi Teknik”. Jakarta: Erlangga.

8. Soewarno. 1995. “Hidrologi (Aplikasi Metode Statistik untuk Analisa Data)”. Bandung: Nova.

9. Sosrodarsono S, Kazuto N. 2000. "Mekanika Tanah dan Teknik Pondasi". Jakarta: PT. Pradnya Paramita.

10. Sosrodarsono, Suyono dan Kensaku Takeda, (2006). "Hidrologi untuk Pengairan", Pradnya Paramita, Jakarta.

11. Sudibyo. 2003. "Teknik Bendungan”, Jakarta: Pradnya Paramita.

12. Triatmodjo, Bambang. 2010. "Hidrologi Terapan". Yogyakarta: Beta Offset.

13. USBR, 1987. Design of Small Dams, US: Government Printing Office.

14. Wildan Syahrir Ridha, 2016. Perencanaan Spillway Morning Glory Pada Bendungan Semantok Nganjuk. Surabaya: Institut Teknologi Surabaya 